\title{
Patient Preference for the Boarding at Emergency Department of Aseer Central Hospital when Emergency is Working with Its Maximum Capacity and Inpatient Admission is Full
}

\author{
Ali Mousa Alahmari ${ }^{1}$, Hassan Abdulrahman Ogran ${ }^{2}$, Abdulrahim Mushabbab Hamhom ${ }^{3}$, \\ Osamah Mohammed Alqahtani ${ }^{4}$, Amal Ali Alahmari ${ }^{5}$, Kamran Mahmood Ahmed Aziz ${ }^{6, *}$ \\ ${ }^{1}$ Consultant and Chairman Energency Department, Aseer Central Hospital, MOH, Saudi Arabia \\ ${ }^{2}$ Internal Medicine Department, Aseer Central Hospital, MOH, Saudi Arabia \\ ${ }^{3}$ Pediatric Neurology Department, Children Hospital, King Fahad Medical City, Riyadh, Saudi Arabia \\ ${ }^{4}$ Bagedo Primary Health Care Center, Al-Madinah Al-Mounawarh, Saudi Arabia \\ ${ }^{5}$ Internal Medicine Department and Aseer Diabetes Center, Aseer Central Hospital, MOH, Saudi Arabia \\ ${ }^{6}$ Aseer Diabetes Center and Emergency Department, Aseer Central Hospital, MOH, Saudi Arabia
}

\begin{abstract}
Overcrowding in Emergency Department usually results in serious consequences such as delay in facilities, medical errors and medical complications as well. This occurs because delay in transfer of the patients from ED to inpatient departments. We conducted this study to know patients' and their attendants preferences to stay in ED or to be shifted to in-patient units. Data was collected via Arabic translated questioner. A total of 316 applicants included in the study (after inclusion / exclusion criteria), 144 patients with 157 patient attendants. $75(52.1 \%)$ were male, while $69(47.9 \%)$ were females. The preferred area for boarding was ED curtained space for $77.8 \%$ of patients and $79 \%$ of patient watcher as compared to $11.8 \%$ patients and $15.3 \%$ attendants who accepted the admission to inpatient hallway (p- value 0.253 ). Regarding the comparison of boarding time ( 8 hours and 24 hours), $55.5 \%$ of patients preferred in ED with 8 hours scenario versus $29.9 \%$ who preferred inpatient hallway ( $\mathrm{p}=0.0897$ ). When 24 hours scenario was compared, it was found that $59 \%$ patients preferred ED while $49.7 \%$ preferred inpatient hallway $(\mathrm{p}=0.252)$. Current study proves that collectively patients prefer to stay in ED (either curtained space or hallway); this is because the patients received quick facilities and attention from the staff. However, with 24 hours scenario, more patients now preferred to stay in in-patient hallway; this is because of delay in transfer of the patients from ED, and delay or lack in facilities which usually occur during overcrowding. We concluded that patient and their preferences differ in different settings. However, overcrowding in ED should be dealt seriously with transfer of patients to in-patient departments / wards as soon as possible to avoid medical errors and complications.
\end{abstract}

Keywords Emergency department, Inpatient, Overcrowding, Boarding, Patients' preference, Cardiovascular mortality

\section{Introduction}

Crowding in Emergency Department (ED) occurs when the identified need for emergency services exceeds available resources for patient care in the emergency department, hospital, or both. It is one of the serious crises that may affect the quality and access to health care. The mortality rate is increased during the crowding time (hazard ratio for death 1.3). Furthermore, there is association of increased risk cardiovascular mortality (cardiac arrest, heart failure,

* Corresponding author:

drkamran9999@yahoo.com (Kamran Mahmood Ahmed Aziz)

Published online at http://journal.sapub.org/cp

Copyright (C) 2018 Scientific \& Academic Publishing. All Rights Reserved myocardial infarction, arrhythmias, stroke or hypotension) with ED crowding and less availability of beds or facilities in in-patient departments. In a systemic review of 93 relevant articles and analysis of crowding in emergency department, it was found that one of the most important factor in ED crowding is boarding patients in ED which have negative impact on patient mortality, management and treatment delays, adverse outcomes and financial burden. . "Boarding" is the process of holding the patient in ED for extended period of time who have been ordered for the admission by a physician with admitting privileges. [1-3]

The unique and important role of emergency departments of the hospitals is now well recognized and calling for 
attention to avoid serious draw-backs. Previous studies have shown that there is increased mortality with more complications if the EDs are crowded with less available facilities. There is sufficient evidence that patient care is worsened by boarding. Evidence-based research demonstrates that boarding results in the delays in care, increased hospital lengths of stay, medical errors, increased patient mortality, financial losses to hospital and physician with medical negligence claims [4] and increased health care cost [5-12]. Hospital overcrowding has adverse effects on critically ill patients as well, and delayed transfer from ED to intensive care units may also result in medical complications $[13,14]$.

It is evident from the current literature and research trials that ED should be reserved for acute or emergency management of the patient. ED is lifesaving facility and should be reserved for such purpose. Boarding in EDs results in shortage of medical facilities and available staff as well. Under any circumstances, EDs should not be utilized for boarding the patients who require admission in in-patient departments. After emergency management, patients should be immediately shifted to concerned in-patient departments for further work up. Hence, by such methodology EDs burden is reduced and facilities are constantly available for the upcoming patients.

Aseer Central Hospital (ACH) is one of the largest tertiary care hospital of Ministry of Health, in Aseer Region of Saudi Arabia. Usually patients are referred from other regions to provide best medical facilities. However, due to overloading by excess referrals and accident/emergency cases, the ED becomes crowded. In this situation, if patients are not discharged (after management) or admitted in the inpatient departments, the ED capacity to manage such patients becomes full and patients have to wait in ED corridors or have to be admitted in the ED curtained rooms. Additionally, new patients find difficulty in their emergency management and even the ED physicians face difficulties to manage these patients. In other words, "boarding" in ED is the most common cause of crowding in the emergency. ACH policy for boarding patient is to keep patients in ED bed in curtained space, not in ED hallway until an available bed in inpatient unit is available. Hence, usually difficulty is faced when inpatient beds are occupied with admission delays. Unfortunately, critically ill patients will wait in a waiting room until bed available for examination.

Hence, and as mentioned above, this study was designed to focus on the patients' preferences during crowding in the ED when inpatient departments are full, and their answers with results of boarding for extended period of time. We plan to focus on the patient problems in ED and, suggested the solution that to admit patient in inpatient hallway (if patient has waited in ED more than $120 \mathrm{~min}$ ), until admission is decided. Based on literature review, and experience of international EDs, our objective was also to perceive the opinion of patients on ED Boarding problem in $\mathrm{ACH}$, and to assess that patients prefer to wait in an ED bed or inpatient hallway and their significant differences.

\section{Methods}

Current study is prospective cross-sectional, observational survey, conducted between June 2016 until July 2016, for a period of one month. Study was approved by institutional board review committee in the hospital. Population of interest were two groups, admitted patients (admitted via ED to inpatient corridor) and patients' attendants / watcher. Patients, attendants and their location was identified from the admission office and we included the patients and their attendants who came through ED. Patients with Communication barriers or disturbed level of consciousness, without attendants, and those who refused to sign the informed consent were excluded from the study. The study was approved by the Aseer Central Hospital Ethical and IRB (Internal Review Board) committee deliberation with reference No. REC \# 2016-06-33. Questioner was adopted from three different sources who worked on boarding problem before and modified to fit for our setup and hospital policies. Original questioner was in Arabic and translated into English by international translation company. Questioner was explained to the patients and attendants. If they were not able to read, then we interviewed them. Data was then entered into the computer and was uploaded to the Google forms on the following websites: (http://goo.gl/forms/hycBbUR8dsJsmWkm2 and http://goo.gl/forms/Q8qLvb9jsCJHRdHE3). Data was then analyzed by the Microsoft Excel software by expert statistician.

\section{Result}

Table 1. Demographic Data and Patients previously admitted in ED with numbers of hours waiting

\begin{tabular}{|c|c|c|c|}
\hline \multicolumn{2}{|c|}{$\begin{array}{l}\text { Sex distribution } \\
(\mathrm{N} ; \%)\end{array}$} & \multicolumn{2}{|c|}{$\begin{array}{c}\text { Number of hours waited in ED } \\
\text { at previous admission }\end{array}$} \\
\hline Male & Female & Hours & N (\%) \\
\hline \multicolumn{2}{|c|}{ Patients } & \multirow{2}{*}{$<6 \mathrm{~h}$} & $8(19.5 \%)$ \\
\hline $75(52.1 \%)$ & $69(47.9 \%)$ & & \multirow{3}{*}{$11(26.8 \%)$} \\
\hline & ants & \multirow[t]{2}{*}{$6-12 \mathrm{~h}$} & \\
\hline $73(46.5 \%)$ & $84(53.5 \%)$ & & \\
\hline \multirow{2}{*}{\multicolumn{2}{|c|}{$\begin{array}{c}\text { Patients admitted before in } \\
\text { emergency department }(\mathrm{N} ; \%)\end{array}$}} & $12-24 \mathrm{~h}$ & $13(31.7 \%)$ \\
\hline & & \multirow{3}{*}{$>24 h$} & \multirow{3}{*}{$9(22 \%)$} \\
\hline Yes & No & & \\
\hline $44 ; 30.6 \%$ & $100 ; 69.4 \%$ & & \\
\hline
\end{tabular}

A total of 316 applicants included in the study (after inclusion / exclusion criteria), 144 patients with 157 patient attendants. 75 (52.1\%) were male, while 69 (47.9\%) were females. This data is shown in table-1, Majority age group range $30-49$ years $31.6 \%$ (44) while the common age group in watcher $18-29$ years $69 \%$ (44), with p- value 0.1 , as shown in table-2. Regarding the patients boarded previously in ED, 44 patients $(30.6 \%)$ had been previously admitted in ED 
because full inpatient units. Majority, $31.7 \%$, stayed in ED 12- 24 hours, and, $22 \%$ stayed more than $24 \mathrm{~h}$ as demonstrated in table-1.

Table-2 demonstrates the age difference in terms of p-values. Overall p-values are 0.1 and 0.3909 .

Table 2. Age distribution for patients and attendants with p-values

\begin{tabular}{|c|c|c|c|c|}
\hline \multicolumn{2}{|c|}{$\begin{array}{c}\text { Age group (years) } \\
\text { and Sex }\end{array}$} & $\begin{array}{c}\text { Patient N (\%) } \\
\text { (Total N=144) }\end{array}$ & $\begin{array}{c}\text { Patient's } \\
\text { watcher N (\%) } \\
\text { (Total N=157) }\end{array}$ & $\begin{array}{c}\text { Overall } \\
\text { P-value }\end{array}$ \\
\hline \multirow{4}{*}{$\begin{array}{c}\text { Age } \\
\text { (years) }\end{array}$} & $<18$ & $12(8.3)$ & $13(8.3)$ & \multirow{2}{*}{0.1} \\
\cline { 2 - 4 } & $18-29$ & $29(20.1)$ & $69(44)$ & \\
\cline { 2 - 4 } & $30-49$ & $44(30.6)$ & $58(36.9)$ & \\
\cline { 2 - 4 } & $50-69$ & $38(26.4)$ & $14(8.9)$ & \\
\cline { 2 - 4 } & $>70$ & $21(14.6)$ & $3(1.9)$ & \\
\hline \multirow{2}{*}{ Sex } & Male & $75(52.1)$ & $73(46.5)$ & \multirow{2}{*}{0.3909} \\
\cline { 2 - 4 } & Female & $69(47.9)$ & $84(53.5)$ & \\
\hline
\end{tabular}

As demonstrated in table- 3 , the preferred area for boarding is ED curtained space for $77.8 \%$ of patients $(\mathrm{N}=112$ patients) and $79 \%$ of patient watcher $(\mathrm{N}=124)$ as compared to $11.8 \%(\mathrm{~N}=17$ patients) and $15.3 \%(\mathrm{~N}=24$ attendants $)$ who accepted the admission to inpatient hallway (p-value 0.253 ).

When ED hallway was compared to inpatient hallway, $41 \%$ preferred to stayed in ED hallway and $39.6 \%$ preferred to shifted to inpatient hallway ( $\mathrm{p}$ - value 0.1576 ).

Table 3. Patient preference for boarding if ED waiting room is full

\begin{tabular}{|c|c|c|c|}
\hline $\begin{array}{c}\text { Preferred area for } \\
\text { boarding }\end{array}$ & $\begin{array}{c}\text { Patient N (\%) } \\
\text { (Total N=144) }\end{array}$ & $\begin{array}{c}\text { Patient's } \\
\text { watcher N (\%) } \\
\text { (Total N=157) }\end{array}$ & $\begin{array}{c}\text { Overall } \\
\text { p-value }\end{array}$ \\
\hline Inpatient hallway & $17(11.8 \%)$ & $24(15.3 \%)$ & \multirow{2}{*}{0.253} \\
\hline ED Curtained space & $112(77.8 \%)$ & $124(79 \%)$ & \\
\hline No preference & $15(10.4 \%)$ & $9(5.7 \%)$ & \\
\cline { 1 - 3 } Inpatient hallway & $57(39.6 \%)$ & $68(43.3 \%)$ & \multirow{2}{*}{0.1576} \\
\cline { 1 - 3 } ED Hallway & $59(41 \%)$ & $71(45.2 \%)$ & \\
\hline No preference & $28(19.4 \%)$ & $18(11.5 \%)$ & \\
\cline { 1 - 3 }
\end{tabular}

Table 4. Best place for boarding if admission unit was not ready within two-time frame $(8 \& 24 \mathrm{~h})$

\begin{tabular}{|c|c|c|c|c|}
\hline Time & $\begin{array}{l}\text { Preferred area } \\
\text { for boarding }\end{array}$ & $\begin{array}{l}\text { Patient N }(\%) \\
(\text { Total } N=144)\end{array}$ & $\begin{array}{c}\text { Patient's } \\
\text { watcher N (\%) } \\
\text { (Total } N=157)\end{array}$ & $\begin{array}{c}P \\
\text { value }\end{array}$ \\
\hline \multirow{3}{*}{$8 \mathrm{~h}$} & $\begin{array}{l}\text { Inpatient } \\
\text { hallway }\end{array}$ & $43(29.9 \%)$ & $66(42 \%)$ & \multirow{3}{*}{0.0897} \\
\hline & $\begin{array}{l}\text { Emergency } \\
\text { Department }\end{array}$ & $80(55.5 \%)$ & $72(45.9 \%)$ & \\
\hline & No preference & $21(14.6 \%)$ & $19(12.1 \%)$ & \\
\hline \multirow{3}{*}{$24 \mathrm{~h}$} & $\begin{array}{l}\text { Inpatient } \\
\text { hallway }\end{array}$ & $43(29.9 \%)$ & $53(33.7 \%)$ & \multirow{3}{*}{0.2052} \\
\hline & $\begin{array}{l}\text { Emergency } \\
\text { Department }\end{array}$ & $85(59 \%)$ & 78 (49.7\%) & \\
\hline & No preference & $16(11.1 \%)$ & $26(16.6 \%)$ & \\
\hline
\end{tabular}

Regarding the comparison of boarding time ( 8 hours and 24 hours), $55.5 \%(\mathrm{~N}=80)$ patients preferred in $\mathrm{ED}$ with 8 hours scenario versus $29.9 \%(\mathrm{~N}=43)$ who preferred inpatient hallway ( $\mathrm{p}=0.0897$ ). When 24 hours scenario was compared, it was found that $59 \%(\mathrm{~N}=85)$ patients preferred $\mathrm{ED}$ while $49.7 \%(\mathrm{~N}=78)$ preferred inpatient hallway $(\mathrm{p}=0.2052)$. These results are shown in table- 4 .

\section{Discussion}

Working in emergency requires skilled persons with prompt actions. However, overcrowding has adverse effects on the health system and may be associated with medical errors [15]. Crowding in ER is related with delay in resuscitation and increased duration of stay in inpatient departments [16-18].

Emergency Department in Saudi Arabia is similar to North American hospitals in the operational and administration systems, with some exceptions in quality and quantity of staffing, number of patients and billing system.

Aseer Central hospital is a tertiary care teaching hospital with well-equipped trauma center. ACH has a capacity of more than 500 beds capacity with 50 ED beds and receives referral from more than 23 General hospitals. Total populations in Aseer provinceis 1,927,087. Annually ED receives approximately 142,495 patients; and the average boarding time for general ward patient and ICU is 10 hours and 10.5 respectively $[19,20]$.

American College of Emergency Physician (ACEP) defines Emergency Medicine as part of the whole institute and has stated that, "Emergency medicine is the medical specialty dedicated to the diagnosis and treatment of unforeseen illness or injury"; and has added, "Emergency Department should not be utilized as an extension of the intensive care and other inpatient units for admitted patients because this practice adversely affects quality of care" [21]. Hence, the Optimal utilization of the emergency department (ED) includes the timely evaluation, management, and stabilization of all patients.

The ACEP has recommended to relocate admitted patients boarding in the emergency department because of lack of available beds on the inpatient units to hallways, conference rooms, or solaria within those inpatient units. With each unit taking a small number of patients, the emergency department can continue to function to care for emergencies, without unduly stressing the inpatient units [21-23].

As demonstrated by our data, studies have also proven that patients usually prefer ward for admission, while waiting in ED [24]. However, some patients may prefer inpatient hallways while awaiting for admissions [25]. Current study proves that collectively patients prefer to stay in ED (either curtained space or hallway; p-values 0.253 and 0.1576 respectively); this is because the patients received quick facilities, attention and prompt action from the physicians and staff. We also compared the data of 8 hours and 24 hours scenario. However, there was a different response. With 24 hours scenario, more patients now preferred to stay in in-patient hallway ( 85 versus $78 ; p=0.252$ ); this is because 
Ali Mousa Alahmari et al:: Patient Preference for the Boarding at Emergency Department of Aseer Central Hospital when Emergency is Working with Its Maximum Capacity and Inpatient Admission is Full

of delay in transfer of the patients from ER, and delay / lack in facilities which usually occur during crowding.

It should be noted that all p-values were not significant; because of our sample size was small. If sample size is increased, the p-values may become significant. However, patient preference may be different from different hospitals depending upon facilities.

If critically ill patients not admitted in respective intensive care units or wards, then overcrowding in ED effects the health care system and may result in mortality as well, as has been shown by recent statistics [26, 27]. Patients with coronary events also suffer with high morbidity and mortality [28].

Hospital workload is usually associated with medical errors and boarding in ED usually is associated with adverse events. We concluded from our research experience and study done in past that ED should deal with specific emergency situations and refer patients as soon as possible to concerned specialties with admissions to avoid overcrowding in ED as overcrowding is associated with mortality with disturbing adverse effects [23, 29-33].

\section{Conclusions}

There is now sufficient compelling data that the boarding the admitted patients in ED has adverse consequences, with high cost, morbidity and mortality. Conversely, decreasing patient boarding in ED results in desirable patient-safety outcomes. Current study data demonstrates such consequences and supports the idea that ED over-crowding should be avoided and critically ill patients requiring admission should be shifted to respective in-patient departments as soon as possible so that new arriving patients to ED can get maximum benefits from the available hospital facilities.

\section{Limitations of the Current Study}

We conduct study in a single site and operations or procedures may be deferent in other hospital in Saudi Arabia or in other country. Our sample size was small. Further multicenter studies are required with large sample size to confirm findings of this study.

\section{REFERENCES}

[1] Nathan RH. Systematic Review of Emergency Department Crowding: Causes, Effects, and Solutions. Ann Emerg Med. 2008; 52: 126-136.

[2] Shari Welech, Emergency Department Performance Measures and benchmarking summit, SAEM society for Acadimic Emergency Medicine doi:10.1197/j.aem.2006.05.026.

[3] Pines JM, Hollander JE. Association between cardiovascular complications and ED crowding. American College of Emergency Physicians 2007 Scientific Assembly; October 8-11, 2007; Seattle, WA.

[4] Dunn R. Reduced access block causes shorter emergency department waiting times: An historical control observational study. Emerg Med (Fremantle). 2003; 15(3), 232-238.

[5] Gibbs N. Do you want to die? The crisis in emergency care istaking its toll on doctors, nurses, and patients. Time. May 28, 1990: 58-65.

[6] Barrero J. Hospitals get orders to reduce crowding in emergencyrooms. New York Times. January 24, 1989: 1-2.

[7] Goldberg C. Emergency crews worry as hospitals say, "Novacancy." New York Times. December 17, 2000: 39.

[8] Orenstein JB. State of emergency. Washington Post. April 22, 2001: B1

[9] Jeffrey NA. Who's crowding emergency rooms? Right now it'smanaged-care patients. Wall Street Journal. July 20, 1999: B1.

[10] Viccellio A, Santora C, Singer AJ, Thode HC Jr, Henry MC. The association between transfer of emergency department boarders to inpatient hallways and mortality: a 4-year experience. Ann Emerg Med 2009; 54: 487-91.

[11] Krochmal P, Riley TA. Increased health care costs associated with ED overcrowding. Am J Emerg Med. 1994; 12(3): 265-266.

[12] Sprivulis PC, Da Silva JA, Jacobs IG, et al. The association between hospital overcrowding and mortality among patients admitted via Western Australian emergency departments. Med J Aust. 2006; 184(5): 208-212.

[13] Cowan RM, Trzeciak S. Clinical review: emergency department overcrowding and the potential impact on the critically ill. Crit Care. 2005; 9(3): 291-295.

[14] Chalfin DB, Trzeciak S, Likourezos A, et al. Impact of delayed transfer of critically ill patients from the emergency department to the intensive care unit. Crit Care Med. 2007; 35(6): 1477-1483.

[15] Kulstad EB, Sikka R, Sweis RT, Kelley KM, Rzechula KH. ED overcrowding is associated with an increased frequency of medication errors. Am J Emerg Med. 2010; 28: 304-309.

[16] Hong KJ, Shin SD, Song KJ, Cha WC, Cho JS. Association between ED crowding and delay in resuscitation effort. Am J Emerg Med 2013; 31: 509-15.

[17] Liew D, Liew D, Kennedy MP. Emergency department length of stay independently predicts excess inpatient length of stay. Med J Aust. 2003; 179(10): 524-526.

[18] Richardson DB. The access-block effect: relationship between delay to reaching an inpatient bed and inpatient length of stay. Med J Aust. 2002; 177(9): 492-495.

[19] Ministry of health strategic plan book 1431-1440 page 23.

[20] General authority of statistics- kingdom of Saudi Arabia, statistics library, service, health.

[21] The American College of Emergency Physicians (ACEP), April 2008. Emergency Department Crowding: High-Impact Solutions, ACEP task force report on Boarding. 
[22] General authority of statistics- kingdom of Saudi Arabia, statistics library, the general population and housing- census 2010, administrative aseer.

[23] Weissman JS, Rothschild JM, Bendavid E, et al. Hospital workload and adverse events. Med Care. 2007; 45(5): 448-455.

[24] Walsh P, Cortez V, Bhakta H. Patients would prefer ward to emergency department boarding while awaiting an inpatient bed. J Emerg Med 2008; 34: 221-6.

[25] Richards JR, Ozery G, Notash M, Sokolove PE, Derlet RW, Panacek EA. Patients prefer boarding in inpatient hallways: correlation with the National Emergency Department Overcrowding Score. Emerg Med Int 2011; 2011: 840459.

[26] Richardson DB. Increase in patient mortality at 10 days associated with emergency department overcrowding. Med J Aust. 2006; 184(5): 213-216.

[27] Burt CW, McCaig LF. Staffing, Capacity, and Ambulance Diversion in Emergency Departments: United States, 2003-04. Advance data from vital and health statistics; no. 376. Hyattsville, MD: National Center for Health Statistics. 2006.
[28] Schull MJ, Morrison LJ, Vermeulen M, et al. Emergency department overcrowding and ambulance transport delays for patients with chest pain. CMAJ. 2003; 168(3): 277-83.

[29] Singer AJ, Thode HC Jr, Viccellio P, Pines JM. The association between length of emergency department boarding and mortality. AcadEmerg Med 2011; 18: 1324-9.

[30] Derlet RW, Richards JR. Overcrowding in the nation's emergency departments: complex causes and disturbing effects. Ann EmergMed. 2000; 35: 63-68.

[31] Weiss SJ, Ernst AA, Nick TG. Relationship between the National ED overcrowding scale and the number of patients who leave without being seen in an academic ED. Am J Emerg Med. 2005; 23: 288-294.

[32] Richardson DB, Bryant M. Confirmation of Association between overcrowding and adverse events in patients who do not wait to be seen. AcadEmerg Med. 2004; 11(5): 462 .

[33] Lie SW, et al. Frequency of adverse events and errors among patients boarding in the emergency department. AcadEmerg Med.2005; 12(5)_suppl_1:49-50. 